\title{
California Wildfire Burns Boundaries Between Science and Art
}

\author{
By Kelsey M. Bisson, Nicholas Baetge, Sasha J. Kramer, Dylan Catlett, Gad Girling, Heather McNair, Eleanor Arrington, \\ Dustin Hayes, Celia Jacobs, Anna James, Ivia Closset, Alexis D. Fischer, Sasha Wagner, Mariah Reading, Jacqueline Comstock, \\ Sarah Amiri, Elizabeth Harvey, Craig Carlson, Peter Gaube, Kyla Drushka, and David L. Valentine
}

Results from our 2017 cruise to the Santa Barbara Channel illustrate the value that student leadership training can bring to ocean science. The Across the Channel: Investigating Diel Dynamics (ACIDD) mission, conducted from December 16 to 22 , 2017, aboard R/V Sally Ride, was led by two PhD students as co-principal investigators and chief scientists (authors Bisson and Baetge). The 21-member science team was composed almost entirely of our graduate student peers at the University of California, Santa Barbara (UCSB), as well as three artists. As an integrated

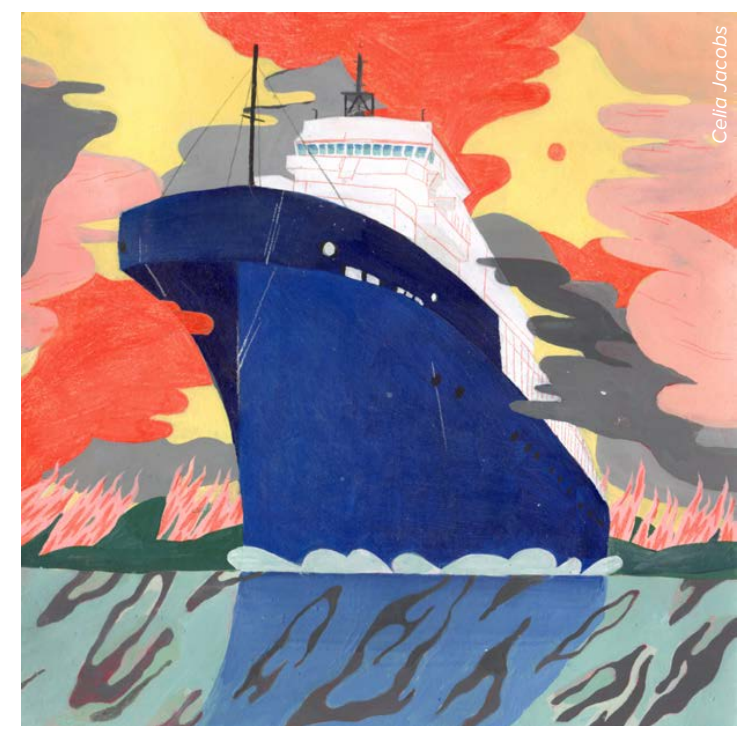

(NAKFI) to fund activities and products designed to bring oceanographic research to the greater public. Experiencing the scientific method through art offers an entry point for the public to examine scientific findings with greater transparency, often spurring more questions from non-experts and promoting deeper trust in the scientific process.

In early 2017, the ACIDD team learned that both the UC Ship Funds and NAKFI proposals were successful. Much of the planning thereafter included acquisition team, we conceived, adapted, and executed research cruise plans and developed far-reaching connections with the public based on our coupled artistic-oceanographic pursuit.

The ACIDD mission was designed to examine fluctuations in microbial, chemical, and biological cycles on daily timescales in the Santa Barbara Channel (SBC), a site with decades of oceanographic research carried out on monthly timescales (e.g., http://www.oceancolor.ucsb.edu/plumes_and_blooms/). Baetge and Bisson also considered that such a cruise offered a great opportunity to share knowledge with the public in order to stimulate environmental curiosity and engagement. They challenged themselves and their scientific team to think creatively about the ways in which oceanography could be communicated to a broader population. With dual goals of gaining a deeper understanding of the SBC and including a diverse public community in the project, Baetge and Bisson submitted a collaborative proposal to the University of California Ship Funds Program. ${ }^{1}$

After the UC Ship Funds proposal was submitted, Bisson led a proposal to the National Academies Keck Futures Initiative of further funding to support consumable, analytical, and artrendering costs. We met weekly and worked closely with Scripps Institution of Oceanography personnel to negotiate logistics, including transportation, space allocation, berths, CTD rosette deployment schemes and water budgets, detailed ship operation schedules, contingency plans, and experimental designs. We were met with the same challenges and obstacles of any major oceanographic program. The team was tasked with adjusting our scientific objectives around the resources we had without abandoning our fundamental directive or jeopardizing the quality of science. We felt as prepared as possible a few weeks before the cruise.

Then, on December 4, 2017, 10 days before mobilization, the Thomas Fire ignited in the Santa Barbara mountains. The fire ultimately burned for over one month, scorching nearly 282,000 acres $\left(1,140 \mathrm{~km}^{2}\right)$ of private, agricultural, and public lands as well as over 1,000 structures throughout Ventura and Santa Barbara Counties (CAL FIRE, https://fire.ca.gov/). At the time, it was the largest wildfire in California's recorded history. Strong Santa Ana winds carried thick plumes of smoke, ash, and soot westward over our study site in the coastal Pacific Ocean.

${ }^{1}$ The University of California Ship Funds Program (https://scripps.ucsd.edu/ships/uc-ship-funds-program) awards sea time aboard Scripps Institution of Oceanography research vessels to proposals that enable practical research training of undergraduate, graduate, and early career scientists from UC Santa Barbara, UC Santa Cruz, and UC San Diego. 
In the week following ignition of the Thomas Fire, the team realized that the fire likely impacted the ecosystem we had anticipated studying. In the last 20 years, fire frequency in Southern California has increased, altering native chaparral ecosystem composition (Syphard et al., 2018). Though the impacts of wildfire ash on freshwater quality and watershed ecosystems in Southern California have been documented (Coombs and Melak, 2013), to our knowledge, there have not been any oceanographic studies addressing the immediate impacts of wildfire ash on marine ecosystems.

The breakout of the Thomas Fire presented a rare opportunity to incorporate a direct investigation of how dry ash deposition impacts the Southern California coastal oceanic ecosystem, with a focus on microbial processes. In the two weeks before mobilization, the science team hastily adapted plans. We redesigned our science questions and tested methods for detecting ash. Ash particles were collected on land to run preliminary experiments, the results of which would guide our sampling strategy at sea. These experiments included measuring nutrient and dissolved organic carbon leached from ash, measuring absorption spectra of varying concentrations of ash particles and ash leachate, quantifying dry ash particle size distribution, and observing the physical behavior of ash in seawater (flocculation, sinking, and buoyancy). While some members of the ACIDD team were working in the lab, others were filming landscapes along the Santa Barbara and Ventura coasts to collect scenes that would be combined with film from the cruise. After the fire broke out, we imagined that a resulting documentary from the cruise could convey the importance of both science and art to society during times of crisis.

During this time, most of the science team members were stressed, scared, and concerned about the welfare of our friends, our neighbors, and ourselves. Shifting wind directions and intensities brought rapidly changing daily evacu- ation orders, with texts and calls sometimes coming in the middle of the night. Final exams for all UCSB students were rescheduled from December to January, so most students returned home. ACIDD team members were some of the only students on campus as we conducted preliminary experiments in labs and repacked gear boxes with newly needed inventory. We worried about the health effects of breathing in ash and smoke, as well as the potential of receiving an order to evacuate our homes at a moment's notice. We waited for news and wondered if our cruise would be canceled. In the days before mobilization, we brought aboard new members who were especially interested in collecting samples to study the real-time effects of ash on microbiology. A subset of our team, professors David Valentine, Craig Carlson, and Debora Iglesias-Rodriguez, applied for an NSF Rapid Response Research (RAPID) grant and quickly received funding to supplement materials for some of the work planned in response to the fire.

On December 14, our mobilization date, the Thomas Fire was only 35\% contained. With mixed emotions, but bolstered as a team, we set sail for the SBC. As the ship neared the channel, settling ash formed a layer on the exterior of the ship, thick enough for writing with a finger. In the days that followed, our teams worked hard, overcoming hurdles to compile an invaluable data set and create stunning artistic representations of the mission.

Art and science both involve an exploratory phase followed by the presentation of results. Scientists are trained to communicate their work in linear, formulaic ways, such as publications that follow a formal structure (introduction, methods, results, discussion), whereas the results of an artistic inquiry may take many forms. While the science necessarily occurs on a slower timeline and many important discoveries are still to be published from this expedition, many of the artistic endeavors evolved quickly and have already been produced.
Our artistic products, introduced below, highlight the intersections of art, science, society, and the rarity of studying the ocean during a natural disaster.

\section{SISTER SCHOOLS}

To engage with students across geographic, socioeconomic, and age boundaries, the ACIDD team adopted 14 "sister schools" from Maine to California. Each participating classroom was sent postcards designed by team member Gad Girling along with some background materials about the science and logistics of ACIDD. After teachers introduced our project to their classes, each student filled out a postcard with questions for the ACIDD team to answer while we were at sea and mailed them back to Santa Barbara. We hoped to give students an opportunity to interact with graduate student scientists despite the physical distance between most of these schools and the SBC (or any ocean). Select postcards were answered and filmed at sea (available at https://vimeo.com/projectacidd) as part of a "Coast to Post" video series. Further communication with schools and teachers took place through Skype calls and the Project ACIDD Instagram account (https://www.instagram.com/ project_acidd/).

\section{ECO ART}

Sampling materials typically used to conduct oceanographic research unavoidably require single-use plastics. These plastics contribute to human-made waste and potentially impact the ocean. To call attention to the amount and types of trash generated from oceanographic work during the Thomas Fire, we teamed up with eco-artist Mariah Reading. Her assemblages featured the single-use trash generated during the ACIDD cruise (e.g., falcon tubes, gloves, containers, tape labels; Figure 1). Her hope is to generate playful and provocative pieces that can spark conversations about the process and methods of science by highlighting the quantity of non-biodegradable materials required to study our environment. 


\section{AQUATIC CATHARTIC DOCUMENTARY}

As part of the effort to engage as many people as possible in the science and process of ACIDD, the art team created a 26-minute documentary titled "Aquatic Cathartic." A short, publicly available documentary film style was chosen with the hope that even the most casually curious viewer could find time to connect with oceanography and art from the convenience of a home computer. The film offers an outsider's perspective to seagoing oceanographic research in all of its glories and shortcomings, highlighting the similarities of life at sea to our civilian struggles and triumphs. The film also emphasizes both the importance and challenges of going to sea during the Thomas Fire. "Aquatic Cathartic" premiered at the Washington, DC, Environmental Film Festival and is now freely available online (https://vimeo.com/281882446).

\section{MIGRATIONS MAGAZINE}

We produced a magazine to document our work at sea. Our society has general perceptions of both art and science as disciplines, and of the separation of the work done in these disciplines. These percep-

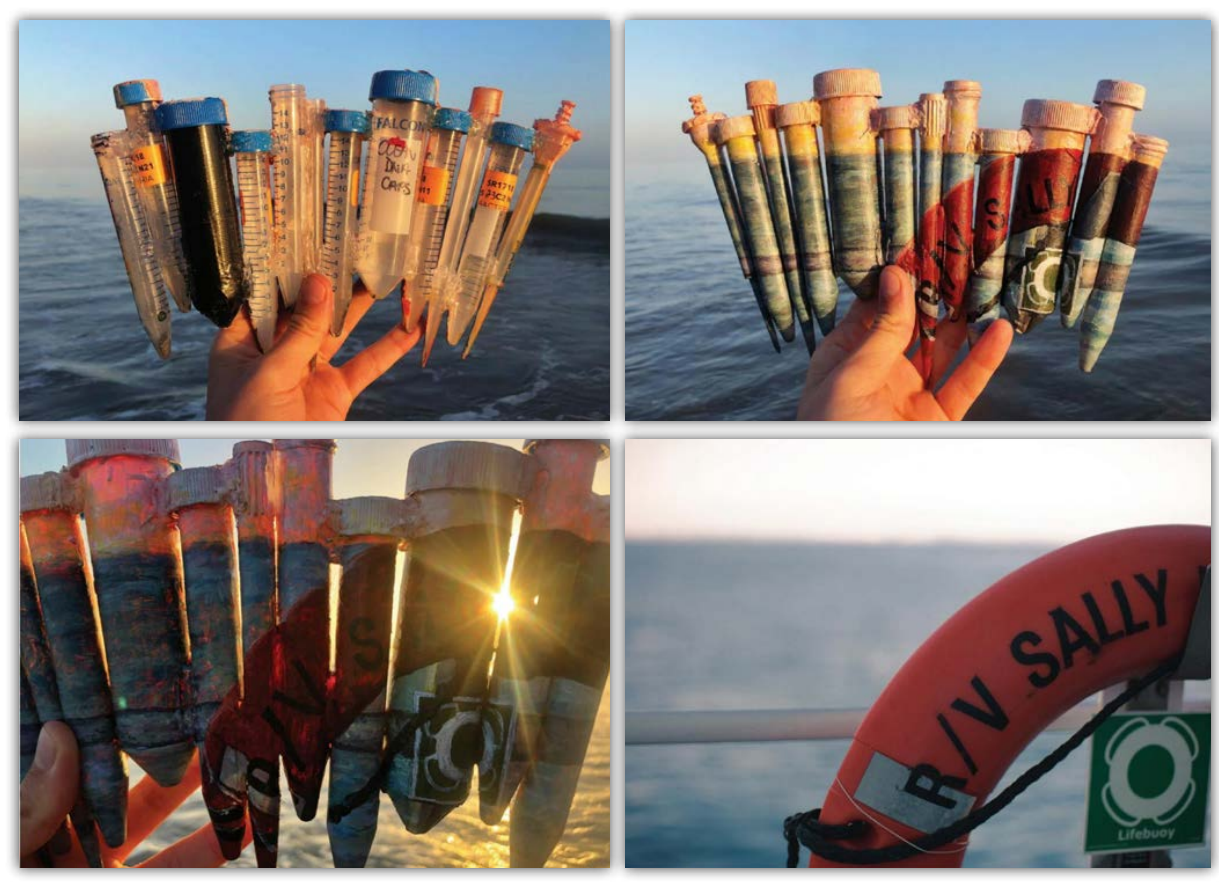

FIGURE 1. Artist Mariah Reading combined falcon tubes into a canvas to capture an R/V Sally Ride scene near sunset. tions are naturally shaped by embedded cultural values that may give inherent value to either discipline, and encourage their separation. The overall goal of Migrations is to flatten these hierarchies in a publication that features contributions across all career stages and disciplines of the ACIDD team. The pages showcase artistic renderings of scientific data juxtaposed with poetry from the science team, photography from the expedition with a focus on ash, and lyrics written aboard R/V Sally Ride (Figure 2). The end result is a creative document where discipline surrenders to the broad subject of "change." We hope this magazine serves as an invitation for readers to ask their own questions outside the boundaries of convention. The magazine was printed and distributed for free at our community event and is freely available online (https://issuu.com/migrationsmag/docs/ finalmigrationszinepages).

\section{COMMUNITY ART AND SCIENCE DAY}

To fully engage the Santa Barbara community in our Thomas Fire experience, in June 2018 we hosted an art and science showcase on the UCSB campus. It was intended as a space for the community to view the work accomplished throughout the ACIDD expedition while affording an opportunity to interact with scientists and ask questions about the impacts of the Thomas Fire on the ocean (or any other questions about the scientific process). In addition to serving as common ground for community conversations, the space was replete with local artists showcasing their work, including giant images of plankton made with a scanning electron microscope, and guests were invited to contribute to a community mural. We also hosted music from local bands, including the band led by the cruise's seagoing musician Dustin Hayes, "Walter Etc." The evening concluded with a screening of the "Aquatic Cathartic" documentary and free distribution of Migrations magazine.

\section{LESSONS LEARNED}

Our graduate student science team came away from this experience with many insights. We found it empowering to plan ship time together and to be PIs with the same responsibility that our mentors would have at sea. We included three artists who brought unconventional equipment and had quite different duties at sea. Despite the alternative aspects of our project, we earned the respect of our mentors, program administrators, and the ship's crew. We advise any future graduate student group in an analogous position to remain confident in their abilities, expertise, and preparation.

One goal of the ACIDD cruise was to learn how the SBC microbiota changed in response to the Thomas Fire, but another goal was to express our process and results to people of varying ages and backgrounds in our community and beyond. Everyone aboard played a different role in accomplishing our goals, and it was important to us that all personnel felt respected and appreciated at sea. Girling designed ACIDD shirts, which were gifted to the crew and science team; Celia Jacobs illustrated portraits of the crew, the science team, and the science itself that were hung throughout the ship; Baetge and Bisson 
worked hard to find effective ways of facilitating good communication between the science team and the ship's crew.

We attribute our successes to good planning and a diverse, cohesive team. Our approach was to "dream big" and then scale back as we met funding or logistical obstacles. The Thomas Fire presented an opportunity to test our cruise plan and our adaptability. While there were disagreements about how to focus our science objectives, which measurements should be given priority, and how the daily plan should be structured, our frequent group meetings ensured that we would be able to contribute compelling products that would outlast the project. The circumstances surrounding the Thomas Fire were challenging and at times seemed to present insurmountable hurdles, but the team dealt with the extra logistical challenges and seized the opportunity to design new projects. The experience taught us the value of teamwork and how to manage and motivate a team successfully.

While it would be unrealistic for every oceanography graduate student to plan a major research campaign, we demonstrated that it is not unrealistic for graduate students to collaborate on projects aside from their dissertations. While some may view side projects as distractions and unnecessary stressors during graduate school, we found that working to create something new together helped to renew our oceanographic inspiration and gave us-this next generation of marine scientists-confidence that we can successfully manage a small research program. Ultimately, the benefits of pursuing this work have far outweighed the drawbacks.

Working together as artists and scientists through a natural disaster reinforced our sense of responsibility to report our findings to our communities. Capturing the wonder of the ocean and sharing it with friends and strangers alike has the power to bring together communities and improve our collective understanding of the ever-changing world in which we live. @e

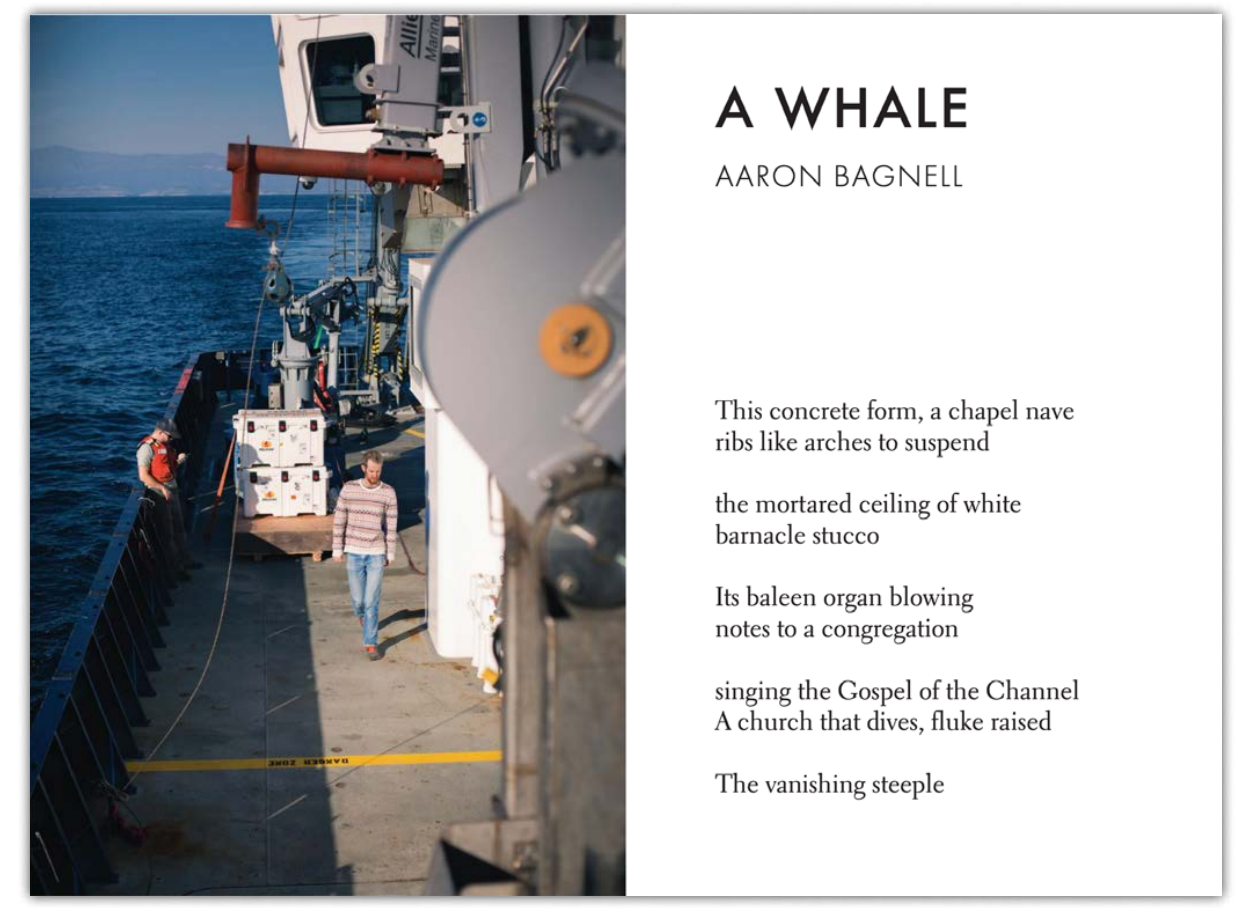

FIGURE 2. Two pages from the cruise magazine Migrations. (left) UC Santa Barbara graduate student and ACIDD science team member Aaron Bagnell walks along the starboard side of R/V Sally Ride during a CTD cast. Photo credit: Gad Girling. (right) A poem by Aaron Bagnell entitled "A Whale."

\section{REFERENCES}

Coombs, J.S., and J.J. Melack. 2013. Initial impacts of a wildfire on hydrology and suspended sediment and nutrient export in California chaparral watersheds. Hydrological Processes 27(26):3,842-3,851, https://doi.org/10.1002/hyp.9508.

Syphard, A.D., T.J. Brennan, and J.E. Keeley. 2018. Diversity of chaparral type conversion to herbaceous vegetation in coastal Southern California. Diversity and Distributions 25:90-101, https://doi.org/10.1111/ddi.12827.

\section{ACKNOWLEDGMENTS}

We are grateful for critical conversations with David Siegel, Emmanuel Boss, JD Talasek, Libe Washburn, Alyson Santoro, Nick Nidzieko, Carter Ohlmann, Dave Karl, B.B. Cael, Debora Iglesias-Rodriguez, and the captain and crew of R/V Sally Ride. Our work could not have been accomplished without logistical support provided by Bruce Appelgate, Zoltan Kelety, Lee Ellett, and Matt Durham at Scripps Institution of Oceanography and sample processing by Crystal Thomas at NASA Goddard Space Flight Center. Thanks to the University of California Ship Funds Program, National Academies Keck Futures Initiative, UCSB's Coastal Fund, NASA grant \#NNX17AK04G, and NSF grant \#1821916 for providing funding for this project.

\section{AUTHORS}

Kelsey M. Bisson (bissonk@oregonstate.edu) was a graduate student at the University of California, Santa Barbara (UCSB), Santa Barbara, CA, USA, and currently is a postdoc in the Department of Botany and Plant Pathology, Oregon State University, Corvallis, OR, USA. Nicholas Baetge (nicholasbaetge@ gmail.com), Sasha J. Kramer, and Dylan Catlett are all PhD candidates at UCSB, Santa Barbara, CA, USA Gad Girling is a graphic artist and videographer in Santa Barbara, CA, USA. Heather McNair was a graduate student at UCSB, Santa Barbara, CA, USA, and is now a postdoc at the University of Rhode Island, Graduate School of Oceanography, Narragansett, $\mathrm{RI}$, USA. Eleanor Arrington is a PhD candidate at UCSB, Santa Barbara, CA, USA. Dustin Hayes is a musician in Ventura, CA, USA. Celia Jacobs is an artist in Los Angeles, CA, USA. Anna James and Ivia Closset are both postdoctoral researchers at UCSB, Santa Barbara, CA, USA. Alexis D. Fischer is a postdoctoral scholar in the Ocean Sciences Department, University of California, Santa Cruz, Santa Cruz, CA, USA. Sasha Wagner is Assistant Professor, Department of Earth and Environmental Sciences, Rensselaer Polytechnic Institute, Troy, NY, USA. Mariah Reading is an artist in the Bangor, ME, USA, area. Jacqueline Comstock is a graduate student and Sarah Amiri is an undergraduate, both at UCSB, Santa Barbara, CA, USA. Elizabeth Harvey is Assistant Professor, Department of Biological Sciences, University of New Hampshire, Durham, $\mathrm{NH}$, USA. Craig Carlson is Professor, UCSB, Santa Barbara, CA, USA. Peter Gaube is Principal Oceanographer and Kyla Drushka is Principal Oceanographer, both at the Applied Physics Laboratory, University of Washington, Seattle, WA, USA. David L. Valentine is Professor UCSB, Santa Barbara, CA, USA.

\section{ARTICLE CITATION}

Bisson, K.M., N. Baetge, S.J. Kramer, D. Catlett, G. Girling, H. McNair, E. Arrington, D. Hayes, C. Jacobs, A. James, I. Closset, A.D. Fischer, S. Wagner, M. Reading, J. Comstock, S. Amiri, E. Harvey, C. Carlson, P. Gaube, K. Drushka, and D.L. Valentine. 2020. California wildfire burns boundaries between science and art. Oceanography 33(1):16-19, https://doi.org/10.5670/ oceanog.2020.110.

\section{COPYRIGHT \& USAGE}

This is an open access article made available under the terms of the Creative Commons Attribution 4.0 International License (https://creativecommons.org/ licenses/by/4.0/), which permits use, sharing, adaptation, distribution, and reproduction in any medium or format as long as users cite the materials appropriately, provide a link to the Creative Commons license, and indicate the changes that were made to the original content. 